University of Nebraska - Lincoln DigitalCommons@University of Nebraska - Lincoln

Faculty Publications from The Water Center

Water Center, The

2015

\title{
Applying a statewide geospatial leaching tool for assessing soil vulnerability ratings for agrochemicals across the contiguous United States
}

Seo Jin Ki

University of Hawaii at Manoa, Honolulu

Chittaranjan Ray

University of Nebraska-Lincoln, cray@nebraska.edu

Mohamed M. Hantush

US Environmental Protection Agency, Cincinnati

Follow this and additional works at: http://digitalcommons.unl.edu/watercenterpubs

Ki, Seo Jin; Ray, Chittaranjan; and Hantush, Mohamed M., "Applying a statewide geospatial leaching tool for assessing soil vulnerability ratings for agrochemicals across the contiguous United States" (2015). Faculty Publications from The Water Center. 34. http://digitalcommons.unl.edu/watercenterpubs/34

This Article is brought to you for free and open access by the Water Center, The at DigitalCommons@University of Nebraska - Lincoln. It has been accepted for inclusion in Faculty Publications from The Water Center by an authorized administrator of DigitalCommons@University of Nebraska Lincoln. 


\title{
Applying a statewide geospatial leaching tool for assessing soil vulnerability ratings for agrochemicals across the contiguous United States
}

\author{
Seo Jin $\mathrm{Ki}^{a}$, Chittaranjan Ray ${ }^{b, *}$, Mohamed M. Hantush ${ }^{c}$ \\ ${ }^{a}$ Department of Civil and Environmental Engineering and Water Resources Research Center, University of Hawaii \\ at Manoa, Honolulu, HI 96822, USA \\ ${ }^{\mathrm{b}}$ Nebraska Water Center, University of Nebraska, Lincoln, NE 68588, USA \\ c National Risk Management Research Laboratory, US Environmental Protection Agency, Cincinnati, OH 45268, USA
}

\section{A R T I C L E I N F O}

Article history:

Received 2 December 2014

Received in revised form

5 March 2015

Accepted 10 March 2015

Available online 1 April 2015

Keywords:

National soil vulnerability maps

Tier 1 assessment

Chemical leaching tool

Subsurface processes

Agrochemical contamination

Diffuse pollution

\begin{abstract}
A B S T R A C T
A large-scale leaching assessment tool not only illustrates soil (or groundwater) vulnerability in unmonitored areas, but also can identify areas of potential concern for agrochemical contamination. This study describes the methodology of how the statewide leaching tool in Hawaii modified recently for use with pesticides and volatile organic compounds can be extended to the national assessment of soil vulnerability ratings. For this study, the tool was updated by extending the soil and recharge maps to cover the lower 48 states in the United States (US). In addition, digital maps of annual pesticide use (at a national scale) as well as detailed soil properties and monthly recharge rates (at high spatial and temporal resolutions) were used to examine variations in the leaching (loads) of pesticides for the upper soil horizons. Results showed that the extended tool successfully delineated areas of high to low vulnerability to selected pesticides. The leaching potential was high for picloram, medium for simazine, and low to negligible for 2,4-D and glyphosate. The mass loadings of picloram moving below $0.5 \mathrm{~m}$ depth increased greatly in northwestern and central US that recorded its extensive use in agricultural crops. However, in addition to the amount of pesticide used, annual leaching load of atrazine was also affected by other factors that determined the intrinsic aquifer vulnerability such as soil and recharge properties. Spatial and temporal resolutions of digital maps had a great effect on the leaching potential of pesticides, requiring a trade-off between data availability and accuracy. Potential applications of this tool include the rapid, large-scale vulnerability assessments for emerging contaminants which are hard to quantify directly through vadose zone models due to lack of full environmental data.
\end{abstract}

(C) 2015 Elsevier Ltd. All rights reserved.

\footnotetext{
* Corresponding author. Tel.: +1 402472 3305; fax: +1 4024723610.

E-mail address: cray@nebraska.edu (C. Ray). 


\section{Introduction}

Maintaining a high quality of groundwater is important for ensuring public health of the nation from its use for drinking water sources (Zogorski et al., 2006). Groundwater in the United States (US) was found to be vulnerable to a mixture of various contaminants, such as nitrate, pesticides, and volatile organic compounds (VOCs) (Nolan and Hitt, 2006; Squillace et al., 2002). Soil and groundwater contamination occurred from intensive human activities in both urban and agricultural areas, e.g., industrial discharges, landfills, hazardous waste dumps, septic tanks, and fertilizer applications (USEPA, 1997; Zogorski et al., 2006). Transport of contaminants, once introduced to the subsurface, was mainly modulated by recharge from precipitation and irrigation (Gilliom et al., 2006). Dissolved contaminants and their metabolites then reached the water table unless they were strongly bound to soils and aquifer media (Gilliom et al., 2006). Detailed information on groundwater contaminants found across the US is provided in recent national monitoring studies, for pesticides (Gilliom et al., 2006) and VOCs (Zogorski et al., 2006) with their degradates (Lawrence, 2006).

Hydrogeologic factors, such as soil permeability (as a function of soil water content), oxygen levels (or aerobic and anaerobic conditions), and flow regimes, were found to be deeply involved in the downward movement of pesticides and VOCs, along with their chemical characteristics (Hantush et al., 2002; Gilliom et al., 2006; Zogorski et al., 2006; Dusek et al., 2011). Simulating water flow and pollutant transport in the subsurface provided a structured approach to analyze the risk of contamination in response to these factors (Dusek et al., 2011; Šimůnek and van Genuchten, 2008). Various models (e.g., MACRO, PRZM3, and HYDRUS) were available that evaluated contaminant leaching in the vadose zone (Holman et al., 2004; Vanclooster et al., 2000). The performance of simulation models varied considerably depending on soil hydrology and contaminant fate and transport processes (Šimunek, 2005). For example, the models that implemented the Richard equation were found to more accurately elucidate subsurface water flux, specifically in an upward direction, than cascading soil water balance models (Vanclooster et al., 2000). This is because cascading models do not account for the effect of soil texture on water movement precisely as well as are dedicated to a top-down (vertical) flow, as their name implies. There have been several studies that attempted to compare estimates of vertical concentration profiles among simulation models for a given scenario in a regulatory context (Dusek et al., 2011; Vanclooster et al., 2000). With increased complexity of modeled processes, a high quality monitoring data set, detailed soil profiles, and extensive computations are typically required to obtain the most accurate simulation results from any of these models (Šimůnek, 2005; Vanclooster et al., 2000). Therefore, simulation models of intermediate complexity or higher cannot be easily applied to large-scale leaching assessments (of pesticides and VOCs) that show high spatial and temporal heterogeneity in environmental conditions.

On the other hand, simple models that require a reduced number of input parameters may delineate the risk of contaminants over large areas, ensuring a rapid diagnosis of soil and groundwater vulnerability (Ki and Ray, 2015; Stenemo et al., 2007). There are some straightforward tools for assessing the leaching potential of pesticides by different input parameters and screening algorithms. Screening Concentration In GROund Water (SCI-GROW; Pereira et al., 2014), Windows Pesticide Screening Tool (WIN-PST; Brown et al., 2011), and statistical regression models of regional and national scales (Stackelberg et al., 2012) are the tools offered at the federal level from the US Environmental Protection Agency (USEPA), Department of Agriculture (USDA), and Geological Survey (USGS), respectively. Attenuation factor (AF), implemented at the State of Hawaii in the US, is a state-level tool used for pesticide evaluation procedure such as pesticide registration and certification (Ki and Ray, 2015; Stenemo et al., 2007). All these tools, except for regression models of the USGS that used additional parameters of watershed characteristics (e.g., air temperature, prevalence of artificial drainage, etc.), were similar in that they included basic information of chemical and soil properties (e.g., chemical half-life and organic matter content), which were widely available, for contaminant leaching assessment (Stackelberg et al., 2012). However, the results of pesticide leaching will not be exactly the same between the tools due to the difference in the assessment algorithms (e.g., linear vs non-linear regression), assumptions (e.g., the presence us absence of advection-dominated flow), and data sets (e.g., sandy soils us agricultural areas) used to derive them (Stackelberg et al., 2012). Although these differences are not significant in some areas, it is generally accepted that physically based screening tools which utilize basic properties that control contaminant movement tend to be more reliable and robust than subjective and empirical approaches. In addition, these empirical approaches of pesticide leaching will not show good performance in leaching assessment of new target compounds that involve the additional upward mass flux from soils such as VOCs (Hantush et al., 2002; Šimůnek et al., 2008; Vanclooster et al., 2000).

The State of Hawaii has recently advanced the physically based assessment tool extended AF (EAF) that can evaluate the leaching potential of VOCs as well as pesticides (Ki and Ray, 2015). As EAF is an extension of previous AF, they share the same information on recharge and soil characteristics, except for new chemical properties of VOCs, to assess contaminant leaching at the state level. In this study, we further expand this work to enhance soil vulnerability assessment in a large scale as this is easily done by replacing recharge and soil properties in Hawaii with those of the contiguous United States. Using this physically based approach, this study would specifically 1) identify risks of soil contamination from volatile and non-volatile chemicals at a national level, 2) estimate pollutant mass loadings in response to national patterns of each pesticide use, 3) examine variation in contaminant leaching by periodic forcing (i.e., monthly recharge and trends of annual pesticide use), and 4) ascertain current bottlenecks and future challenges of EAF in chemical leaching assessment. We hope that the proposed methodology plays an important role in addressing regional or national soil and groundwater pollution issues from various types of contaminants such as emerging contaminants that are a lack of information for detailed simulation. 


\section{Materials and methods}

\subsection{Screening model for agricultural chemicals}

Hantush et al. (2002) developed an analytical model for describing non-conservative leaching behavior of VOCs in soils. This model estimated the mass fraction profile of VOCs in the depth of the crop root zone in terms of leaching, volatile loss, and degradation. By ignoring the effect of diffusion in the leaching portion (i.e., assuming advection-dominated reactive transport), the mass fraction of VOCs available for leaching below the root zone depth can be written as:

$E A F=\frac{M_{r}}{M_{0}}=\frac{q}{q+\left(K_{h} \cdot D_{g} / l\right)} \cdot \exp \left(\frac{-\ln (2) \cdot \theta_{F C} \cdot E R F \cdot d}{T_{1 / 2} \cdot q}\right)$,

where $E R F=1+\frac{\rho_{b} \cdot f_{\text {oc }} \cdot K_{\mathrm{oc}}}{\theta_{\mathrm{FC}}}+\frac{n_{a} \cdot K_{h}}{\theta_{\mathrm{FC}}}$.

Here, EAF and ERF are expanded attenuation factor and expanded retardation factor, respectively. These two terms are analogous to the well-known dimensionless indices of pesticide leaching, AF (an indicator of soil attenuation capacity only for non-volatile chemicals) and retardation factor (RF; an indicator of soil retardation capacity only for nonvolatile chemicals). Note that in a similar manner, EAF and ERF indicate soil attenuation and retardation capacities, respectively, for both volatile and non-volatile chemicals. In the above equations, EAF and ERF newly include the term in front of the exponential function, and the last term often canceled for simplicity from the two traditional indices (i.e., $\mathrm{AF}$ and $\mathrm{RF}$ ), respectively. $\mathrm{M}_{r}[\mathrm{M}]$ represents the residual mass at an arbitrary soil depth $d[\mathrm{~L}]$ after applying an initial mass $M_{0}$ $[\mathrm{M}]$ to the soil surface. 1 signifies a stagnant air boundary layer thickness [L] which is imposed as the upper boundary condition at the soil surface. The chemical properties of VOCs are reflected in both EAF and ERF; $K_{h}=$ the dimensionless Henry's constant $[-], D_{g}=$ the diffusion coefficient in soil $\left[\mathrm{L}^{2} / \mathrm{T}\right], \mathrm{T}_{1}$ ${ }_{2}=$ the half-life (that accounts for all kinds of loss in aggregate) $[\mathrm{T}]$, and $\mathrm{K}_{\mathrm{oc}}=$ the soil sorption coefficient $\left[\mathrm{L}^{3} / \mathrm{M}\right]$. The remaining parameters, except for the groundwater recharge rate $q$ (more precisely, it represents the average soil water flux and its direct use as net groundwater recharge may underestimate leaching potential) [L/T], indicate the physical properties in soils; $\theta_{F C}=$ the soil moisture content (correctly, average $\theta$ values measured from county soil surveys should be used) $[-], \rho_{b}=$ the bulk density $\left[\mathrm{M} / \mathrm{L}^{3}\right], f_{\text {oc }}=$ the organic carbon content [-], and $n_{a}=$ the air-filled porosity [-]. Using the index EAF, we assessed the relative leaching potential of volatile and non-volatile chemicals in various soils of the contiguous United States; 0 for complete attenuation and 1 for no attenuation. Note that while we simply use commonly available properties to introduce its applicability, some parameters (e.g., q, $\theta, \mathrm{T}_{1 / 2}$, and $\mathrm{K}_{\mathrm{oc}}$ ) need to be carefully determined for more correct assessment of chemical leaching at the desired scale. For example, a soil water balance approach can be used to compute $q$ as part of the model with evapotranspiration data in specific areas. The half-life of a chemical is further adjusted to target regions using a correction equation or procedure associated with (soil) temperature, soil moisture, and depth of interest (Beulke et al., 2002; Šimůnek et al., 2008). There are also certain conditions that affect sorption and degradation of a particular chemical simultaneously (Beulke et al., 2002). For example, when their behaviors are strongly dependent on $\mathrm{pH}$, these values should be specified seriously for other real world assessments. Previously, we addressed all of the uncertainty in these parameters with first order uncertainty analysis (Ki and Ray, 2015). The analytical solution for the transport of VOCs in soils is discussed in detail by Hantush et al. (2002).

\subsection{Major database updates}

As shown in the equation above, EAF requires databases of soil, chemical, and recharge parameters to provide a benchmark indicator for leaching of agricultural pollutants. Table 1 shows a list of open geospatial layers that are used for pollutant leaching assessment at a national scale. Among two types of soil maps, we used the general soil map (so-called STATSGO2; Soil Survey Staff, 2013b) which defined soil properties more broadly than the detailed soil map (so-called SSURGO; Soil Survey Staff, 2013a) for a national-scale leaching assessment. This is because the use of STATSGO2 significantly reduces computation time and data storage resources involved in assessment. Also, the SSURGO data sets currently do not cover the entire soil survey areas of the US (Soil Survey Staff, 2013a). Note that SSURGO and STATSGO2 indicate digital soil maps in the US provided at high (at 1:12,000 or 1:24,000 scale) and medium spatial resolutions (at 1:250,000 scale), respectively. Fig. 1a presents two letter abbreviations of the lower 48 states in the US examined for this study. Additional information concerning full state names and their spatial information can be found in Table A.1.

To compile the new soil database, the STATSGO2 data sets which included both spatial layers and tabular data were retrieved for individual states. Then, important topsoil parameters of $\rho_{b}, \theta_{\mathrm{FC}}$, and $f_{\text {oc }}$ (at $0-0.5 \mathrm{~m}$ depth) incorporated in EAF were estimated from a large array of the tabular data using queries in the Microsoft (MS) Access Database Template (i.e., soildb_US_2002.mdb) provided by the USDA-Natural Resources Conservation Service (NRCS). The table arranged by the basic geographic unit (i.e., soil map units) in MS Access was extracted to an excel file, which was joined with the spatial layer (i.e., soil polygons) of each state based on the common attribute field between two tables (i.e., map unit symbol MUSYM or map unit key MUKEY). Note that while MUSYM is an identifier of labeling each soil series, MUKEY consists of a unique numerical key for the map unit. Both MUSYM and MUKEY are used to join or relate soil polygons to other attribute tables (i.e., physical and chemical properties). Finally, all spatial layers in individual states were combined into a single shapefile for the 48 contiguous states in the US (Fig. $2 \mathrm{a}-\mathrm{c}$ ). The total size of soil database for the 48 US states was 1.04 gigabyte (after extracted from individual compressed files), which was further reduced to 407 megabyte in a single shapefile.

The database for aquifer recharge covering the lower 48 US states was simply retrieved from a previous study conducted by the USGS (Wolock, 2003). This study estimated the mean groundwater recharge in unit of $\mathrm{mm} /$ year based on the base flow index for a given year (i.e., the percentage of base flow to 


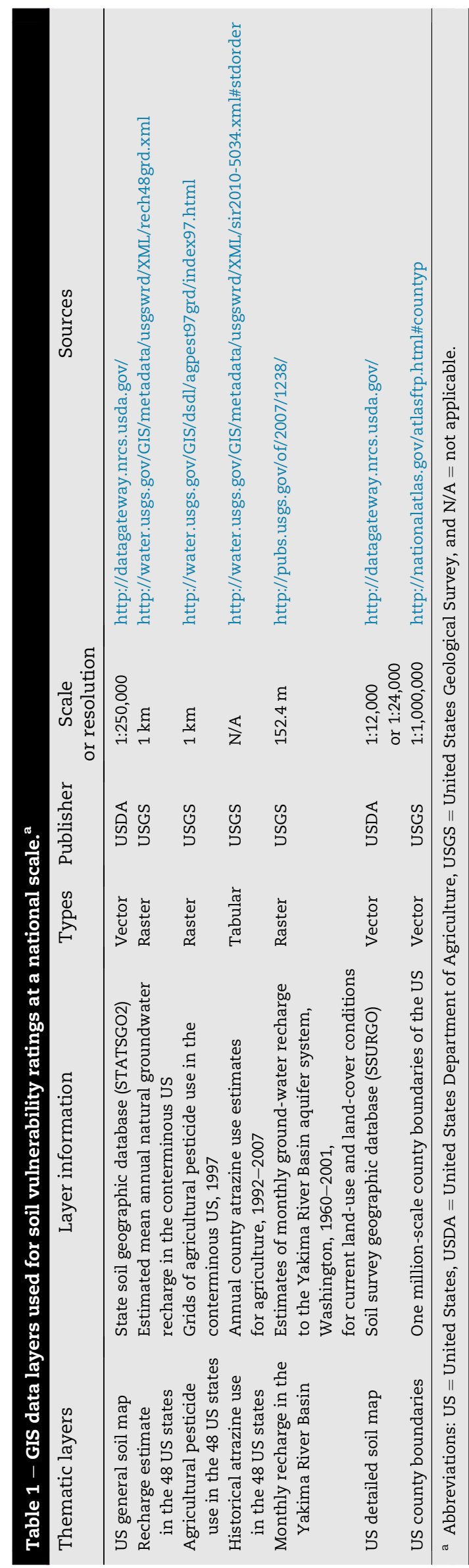

total stream flow) and average annual runoff between 1951 and 1980. The resulting map represents the long-term average recharge rates. There are various methods (e.g., water budget, groundwater, and watershed models) that estimate natural groundwater recharge at different spatial and temporal scales (Risser et al., 2005). Depending on the available data, any of these can be used to renew the national and statewide groundwater recharge maps later, as discussed briefly in Section 2.1. The national-scale recharge map obtained from the previous study is illustrated in Fig. $2 \mathrm{~d}$.

The chemical database of volatile and non-volatile chemicals was newly developed for the regional pollutant leaching assessment in the State of Hawaii (Ki and Ray, 2015; Stenemo et al., 2007). This database was constructed from various data sources including the Pesticides Properties DataBase of the Agriculture and Environment Research Unit in the United Kingdom (so-called PPDB; UH, 2013), the Pesticide Properties Database of the USDA-Agricultural Research Service (so-called PPD; Herner and Acock, 2003), and the handbook on chemicals (Mackay et al., 2006). Table 2 presents chemical properties of 5 example compounds, which are used for the national assessment of chemical leaching, out of 52 chemicals applied to the tool in the State of Hawaii (Ki and Ray, 2015). Finally, implementing all the databases with EAF in a geographic information system (i.e., ArcGIS 10.0) using Visual Basic code (i.e., VB 6) provided the national soil vulnerability maps that differed by chemicals, soils, and recharge rates.

\subsection{Compilation of other databases}

To examine benefits and drawbacks of the developed index EAF, we also compiled additional geospatial layers for pollutant leaching assessment at the national scale. These included maps related to the agricultural pesticide use in 1997, historical usage of atrazine from 1992 to 2007, monthly recharge in the Yakima River Basin in 2001, and detailed descriptions of the soils (see Table 1). Fig. 1b illustrates areas of study for the Yakima River Basin at Washington as well as for the two test areas of spatial resolution analysis on different soil maps (i.e., Mariposa County at California and Custer County at Nebraska) in the US mainland. In the figure, black and gray lines indicate state and county boundaries, respectively.

The raster data set of the agricultural pesticide use for 1997 was used to associate it with the benchmark indicator (i.e., EAF) for chemical leaching. For example, multiplying the total amount of a particular pesticide applied by its leaching fraction provides a robust load estimate that reflects the proper loading conditions in the field. The resulting load will be represented as the mass of a pollutant available for leaching at a vertical depth below $0.5 \mathrm{~m}$. However, note that the screening depth is flexible in the model depending on the depths of soil profile database selected. Similarly, annual atrazine use patterns for each county during 1992-2007 were used to calculate pollutant loads of atrazine in different years. Specifically, this data set was joined with polygons depicting county boundaries in the US as it was offered in tabular formats (see Table 1).

The average monthly recharge map in the Yakima River Basin (see Fig. 1b), provided in a raster format (Vaccaro and 
(a)

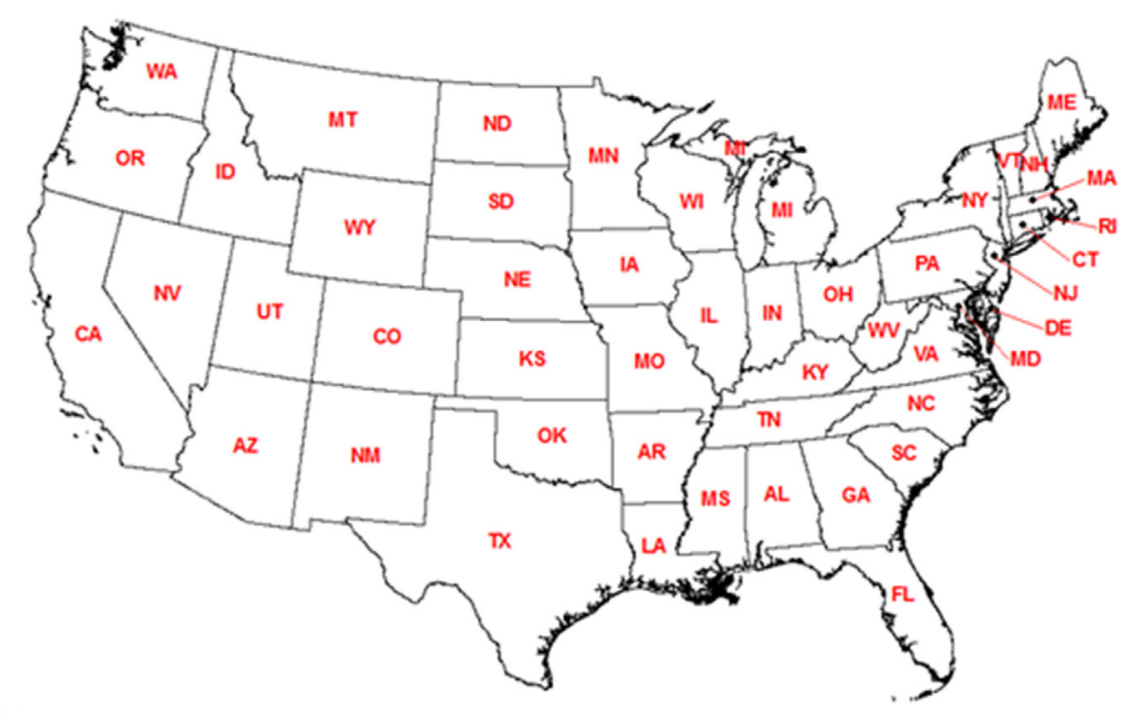

(b)

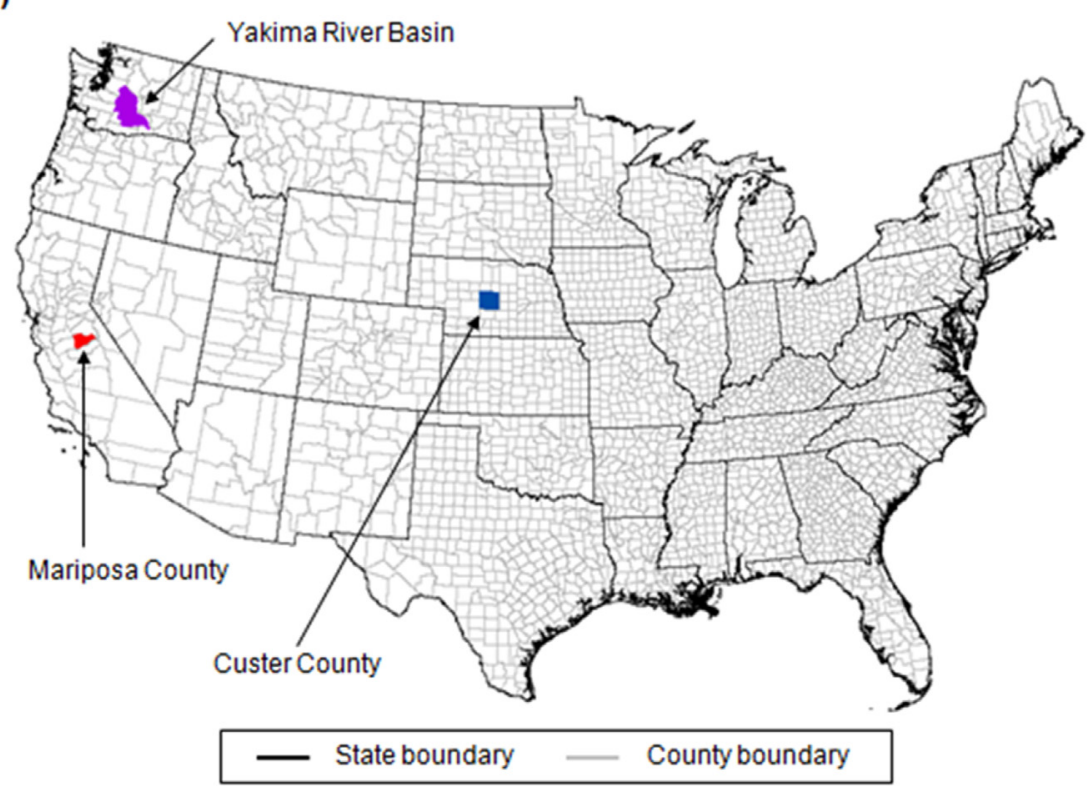

Fig. 1 - Maps of the contiguous United States (US) with state (black line) and county boundaries (gray line, see Table 1); (a) postal abbreviations for all 48 US states and (b) three test areas for the Yakima River Basin in Washington (WA), Mariposa County in California (CA), and Custer County in Nebraska (NE). Full names of the $\mathbf{4 8}$ states are given in Table A.1.

Olsen, 2007), was used to examine the variation of chemical leaching in accordance with changes in groundwater recharge rates in water year 2001. This study estimated daily recharge rates using two hydrologic models, i.e., Precipitation-Runoff Modeling System (PRMS) and Deep Percolation Model (DPM), in the USGS Modular Modeling System during 1960-2001, and aggregated them on monthly basis in terms of hydrologic response units (i.e., HRUs). Note that PRMS refers to a distributed-parameter modeling system to simulate surface water hydrology, whereas DPM is a water-budget model used for deep drainage (i.e., groundwater recharge) estimation. Also, the term HRUs, frequently used in water resources engineering, indicates homogeneous spatial units discretized (or subdivided) from each sub-basin.
The total number of grid cells in a raster data set created from these HRUs was 78,144.

We also compared the difference of chemical leaching between STATSGO2 and SSURGO as many hydrologic modeling studies emphasized the importance of spatial resolution of input maps (e.g., digital elevation model) in simulation results (Gassman et al., 2007). Generally speaking, while the minimum resolution to compute EAF is not determined explicitly, the prediction result cannot be more accurate than the lowest map resolution among input layers (e.g., soil and recharge maps). Two counties (i.e., Mariposa in California and Custer in Nebraska) that showed different recharge patterns (high us low recharge rates), as shown in Fig. 2d, were selected to verify this approach. 
(a)

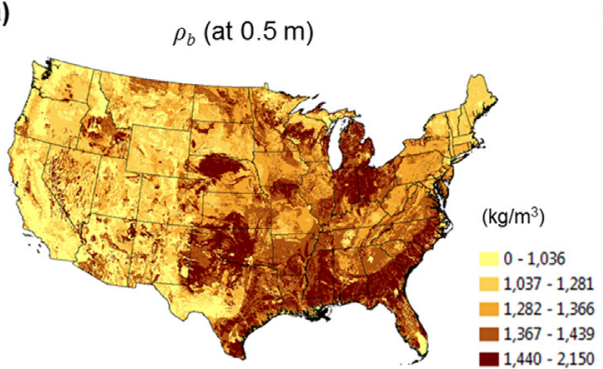

(b)

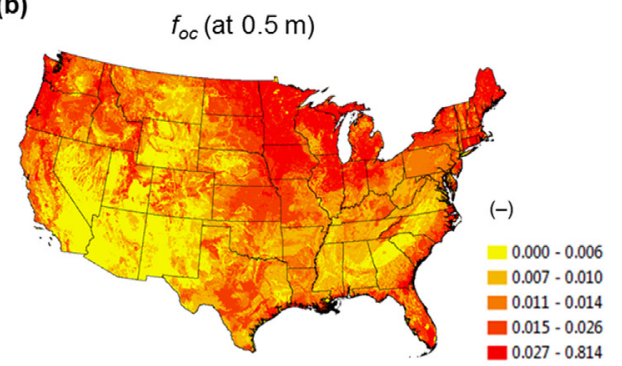

(c)

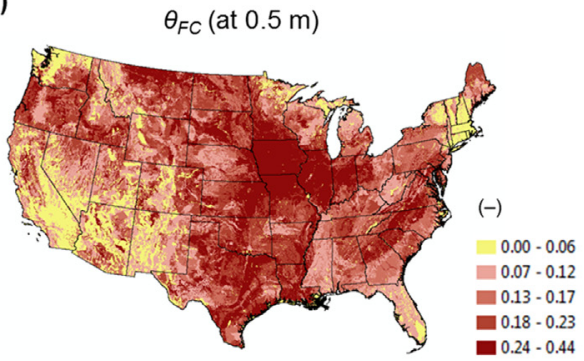

(d)

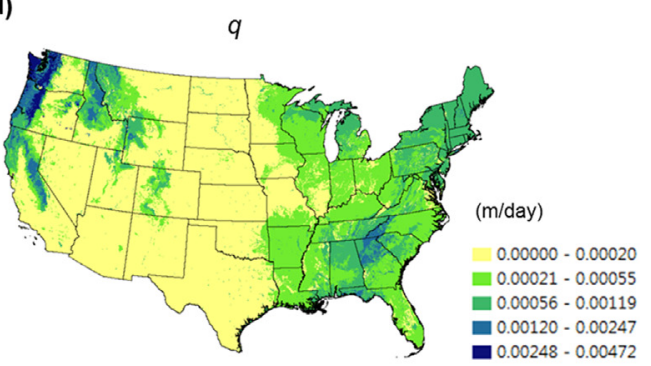

Fig. 2 - Soil and recharge properties in the contiguous United States compiled from STATSGO2 and a previous study in USGS (see Table 1); (a) $\rho_{b}\left(\mathrm{~kg} / \mathrm{m}^{3}\right)$ at $0.5 \mathrm{~m},\left(\right.$ b) $f_{\text {oc }}(-)$ at $0.5 \mathrm{~m}$, (c) $\theta_{F C}(-)$ at $0.5 \mathrm{~m}$, and (d) q (m/day).

\section{Results and discussion}

\subsection{National-scale soil vulnerability assessment}

Fig. 1 illustrates soil and recharge parameters $\left(\rho_{b}, f_{\mathrm{oc}}, \theta_{\mathrm{FC}}\right.$, and $\left.q\right)$ in the contiguous United States used to estimate chemical leaching potential using EAF. The soil bulk density was found to be high on the (lower) right side of the US mainland, whereas the upper and middle parts of soils showed high organic carbon content. A negative correlation was generally observed between the bulk density and organic carbon content, some soils had unique characteristics in terms of a positive relationship between them (see soils in $\mathrm{MI}, \mathrm{IN}, \mathrm{OH}$, and FL as well as those of WY, UT, CO, AZ, and NM). Most of soils in the US mainland, except for some of western and northeastern states, showed medium to high moisture content. The groundwater recharge rate was generally high in the mountains along the Pacific Coast region (the west coast of WA and OR and the north and mountainous parts of CA), medium in the east side of the US mainland, and very low in the remaining areas (the North and South Central Regions or the Mountain West and Middle States Regions).

\subsubsection{Screening indicator for pollutant leaching}

Combining these soil and recharge parameters with the chemical properties of (volatile and non-volatile) compounds results in soil vulnerability maps that depict the potential risk of contaminant leaching at $0.5 \mathrm{~m}$ depth (Fig. 3). In Fig. 3, the leaching potential of each compound is indicated by a color index which ranges from very low through medium to very high with showing the absence of available soil data (e.g., $\rho_{b}$ and/or $\theta_{F C}$, see white color). Among the four chemicals examined, glyphosate presented the lowest level of leaching due to high $K_{o c}$ and relatively short average $T_{1 / 2}$ values (see Fig. $3 \mathrm{~b}$ and Table 2). The chemical simazine showed slightly higher leaching potential than 2,4-D because of a prolonged persistence (i.e., long $T_{1 / 2}$ ) in the soils, although it had greater tendency to bind to soils than 2,4-D (see Fig. $3 a$ and $d$ ). In particular, the areas of low to extensive leaching of simazine appeared to coincide with high recharge rates, in addition to soil physical properties (e.g., low to medium $f_{\text {oc }}$ ), to a lesser extent (see Fig. 2d). The highest level of leaching was observed for the chemical picloram due to very low $K_{o c}$ and long $T_{1 / 2}$ values (see Fig. $3 c$ and Table 2). The leaching potential of picloram was significantly high in most parts of the US mainland, excluding some of the central US where recharge

Table 2 - Chemical properties of selected pesticides compiled for the national soil vulnerability assessment. ${ }^{a}$

\begin{tabular}{|c|c|c|c|c|c|c|c|c|c|c|}
\hline \multirow[t]{2}{*}{ Chemicals } & \multirow[t]{2}{*}{ CAS numbers } & \multirow{2}{*}{$\begin{array}{c}\text { USGS parameter } \\
\text { codes }\end{array}$} & \multicolumn{2}{|c|}{$K_{\mathrm{OC}}\left(\mathrm{m}^{3} / \mathrm{kg}\right)$} & \multicolumn{2}{|c|}{$\mathrm{T}_{1 / 2}(\mathrm{~d})$} & \multicolumn{2}{|c|}{$K_{h}(-)$} & \multicolumn{2}{|c|}{$D_{g}\left(\mathrm{~m}^{2} / \mathrm{d}\right)$} \\
\hline & & & Average & $\mathrm{SD}$ & Average & $\mathrm{SD}$ & Average & SD & Average & $\mathrm{SD}$ \\
\hline 2,4-D & $94-75-7$ & 39732 & 0.053 & 0.022 & 11.667 & 3.141 & $1.0 \times 10^{-6}$ & $1.0 \times 10^{-6}$ & 0.479 & 0.043 \\
\hline Atrazine & $1912-24-9$ & 39632 & 0.126 & 0.056 & 61.625 & 31.172 & 0 & 0 & 0.472 & 0.022 \\
\hline Glyphosate & $1071-83-6$ & 62722 & 1.669 & 0.922 & 27.578 & 14.412 & 0 & 0 & 0.421 & 0.088 \\
\hline Picloram & 1918-02-01 & 49291 & 0.023 & 0.012 & 869.145 & 2564.592 & 0 & 0 & 0.449 & 0.037 \\
\hline Simazine & $122-34-9$ & 04035 & 0.137 & 0.033 & 86.917 & 49.253 & 0 & 0 & 0.333 & 0.127 \\
\hline
\end{tabular}

a Abbreviations: CAS = Chemical Abstract Service, USGS = United States Geological Survey, and SD = standard deviation. 
(a)

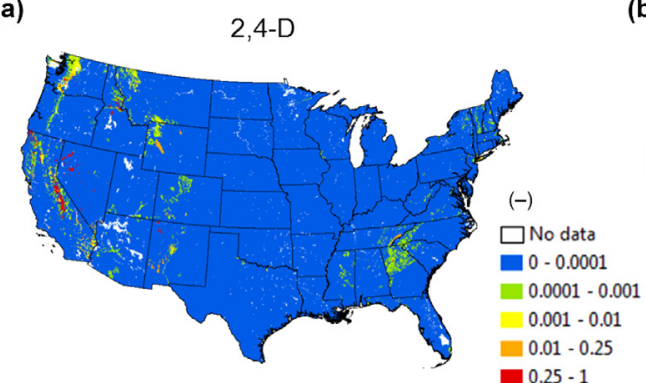

(b)

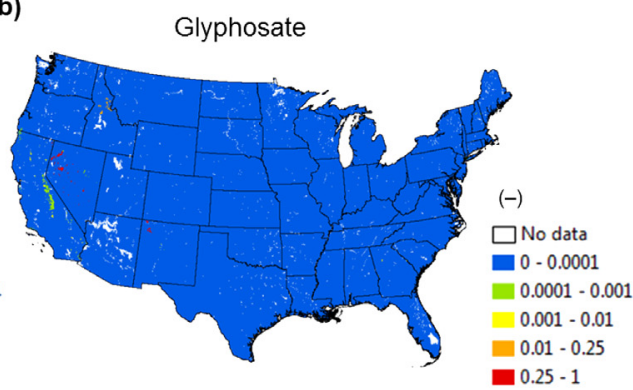

(c)

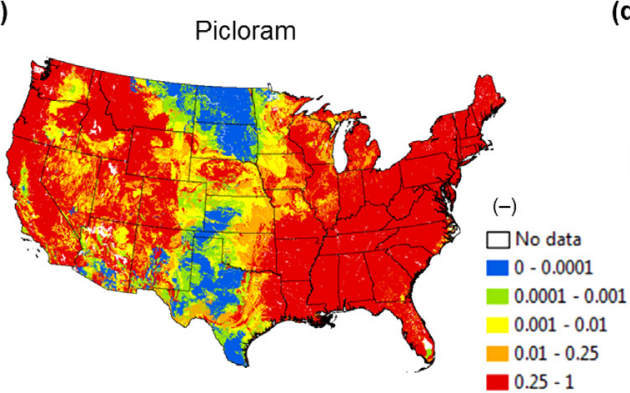

(d)

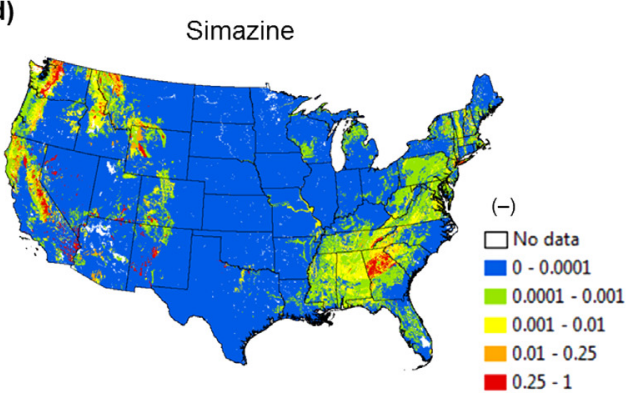

Fig. 3 - Leaching potential of four chemicals in the contiguous United States assessed by extended attenuation factor (EAF); (a) 2,4-D, (b) glyphosate, (c) picloram, and (d) simazine. Color index indicates a leaching fraction of a chemical at $0.5 \mathrm{~m}$ depth; blank (no data), 0-0.0001 (very low), 0.0001-0.001 (low), 0.001-0.01 (medium), 0.01-0.25 (high), and 0.25-1 (very high). (For interpretation of the references to color in this figure legend, the reader is referred to the web version of this article.)

rates were the lowest (see Fig. 2d). Our previous study demonstrated that $f_{\text {oc }}$ and $q$ were ranked second and fifth, respectively, in order of importance among 11 parameters employed in EAF (Ki and Ray, 2015). In addition, the soil properties of $\rho_{b}$ and $\theta_{F C}$ were ranked ninth and tenth tested within the range of plausible parameter values at the State of Hawaii, respectively.

\subsubsection{Mass load estimation from pesticide usage patterns} Multiplying the leaching index map of a chemical (Fig. 3) by the total amount of the product used (Fig. A.1) allows us to estimate contaminant mass load at shallow soil horizons in the contiguous United States (Fig. 4). Fig. A.1 shows agricultural use of four chemicals for 1997 in the US mainland at $1 \mathrm{~km}$ spatial resolution (see also Table 1). As shown in the figure, the intensity of pesticide use varied widely across contaminants as well as among states. Specifically, some areas did not use a particular pesticide at all (see white space inside the boundaries in Fig. A.1a-d), implying major agricultural crops produced significantly varied among US states. Fig. 4 illustrates the mass loadings of chemicals available for leaching at $0.5 \mathrm{~m}$ depth below. Example load estimation for picloram is given in Fig. $4 \mathrm{a}$. In the figure, the contaminant mass load is concentrated in the middle and upper left sides of the US mainland, in accordance with the intensive use of picloram. Note that the loading estimate of picloram in WA, OR, ID, and UT, specifically including NV, appeared to be slightly overestimated due to the low resolution of pesticide use maps covering a large area. Fig. 4b shows the summary results of four contaminant mass loads aggregated for individual states. As shown in the figure, the chemical picloram recorded the largest contaminant load, in comparison to other chemicals, in the middle left side of the US mainland (e.g., MT, WY, NE, and TX). Conversely, negligible amounts of 2,4-D and glyphosate were likely to be leached (Fig. $4 \mathrm{~b}$ ) even though huge quantities of chemicals were used on different agricultural fields (Fig. A.1a and b). Simazine was the highest in CA, followed by FL, VA, and NY.

\subsection{Variation in contaminant leaching by periodic forcing}

3.2.1. The influence of groundwater recharge on contaminant leaching

Fig. 5 illustrates the effect of groundwater recharge on contaminant leaching in the Yakima River Basin Aquifer system using EAF. Fig. 5a shows the monthly recharge rates, which are aggregated for each month, in the water year 2001 that spans from October of 2000 until September of 2001. As shown in the figure, the recharge rates from January to May were higher than the other months, and most of the recharge occurred in the upper part of the basin. Fig. $5 \mathrm{~b}$ presents a corresponding change in leaching of an example chemical simazine in response to different recharge rates. In the figure, a color index indicates the risk associated with contaminant leaching at a soil depth of $0.5 \mathrm{~m}$, as described in Fig. 3. The leaching potential of simazine was typically very high in the upper basin during January through May, which coincided with the periods and areas of high recharge rates. However, there were also many other areas in the basin that exhibited medium to high simazine leaching which was independent of groundwater recharge (see black arrows in Fig. 5b). Specifically, these areas appeared to be more vulnerable than remaining areas to soil and groundwater contaminants due to intrinsic soil properties such as low $f_{\text {oc }}$. Therefore, groundwater recharge and soil parameters in EAF effectively 
(a)

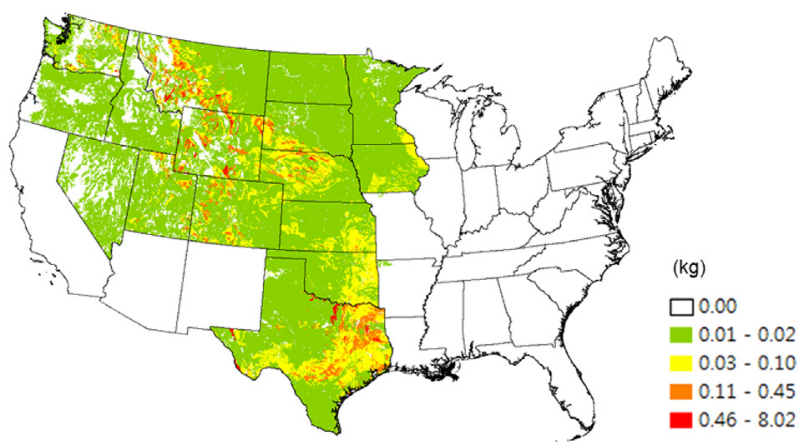

(b)

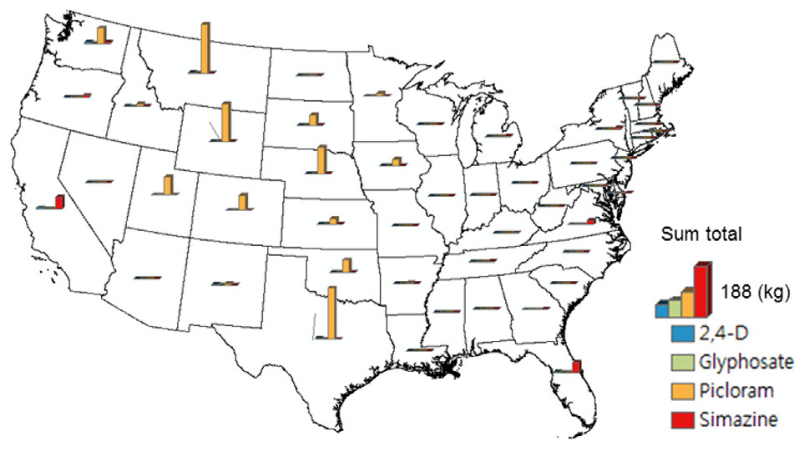

Fig. 4 - Load estimates of four chemicals (available for leaching at $\mathbf{0 . 5} \mathrm{m}$ depth) in the contiguous United States; (a) an example of picloram and (b) the sum of pollutant loads for four chemicals (i.e., 2,4-D, glyphosate, picloram, and simazine) in each state.

modulate contaminant leaching in the soils, as discussed briefly in Section 3.1.1. Note that the leaching of simazine is estimated based on digital data sets of soil and recharge maps as well as its chemical characteristics, without information on actual pesticide use in the basin.

3.2.2. The influence of pesticide application on load estimation Being successful rigorously, the index EAF should also calculate the amount of contaminant leaching that is correlated with pesticide use at field level. Fig. 6 shows the effect of historical pesticide use on contaminant leaching in the contiguous United States using EAF. The annual atrazine use available publicly from 1992 to 2007, which is aggregated for each state, is illustrated by different symbols and colors (in the web version) in Fig. 6a, as an example of a national estimate of contaminant load. As presented in Fig. 6a, there were wide variations in atrazine use among states as well as across years for a given state. In particular, the historical atrazine use in AZ, MT, and UT varied more widely than other states. The states IL, NE, and IA, followed by KS, and IN, recorded the most intense atrazine use in agricultural activities. Fig. $6 \mathrm{~b}$ describes the variations in the mass loadings of atrazine predicted by EAF in response to its temporal usage patterns for the 16 years. The same approach, as done in Section 3.1.2, was applied to this load estimation, which was then accumulated for individual states. The highest atrazine loading was observed in FL, followed by WA, CA, NY, and NM, indicating the soils in these five states had the lowest capacity for pollutant attenuation.
Interestingly, some states that showed a large amount of atrazine use presented either the highest attenuation capacity (for IA, KS, and NE) or wide variations in different years (for $\mathrm{CO}$ ) or possibly both (for $\mathrm{MN}$ ). In the same sense, there were also a few states which showed the reverse attenuation pattern that the low atrazine use caused the high load of atrazine (for AZ and CA). Finally, the soils in ND appeared to have the highest capacity to retain or degrade atrazine. Their annual load patterns were not presented because of very low values less than $1 \mathrm{~kg}$, so left blank in the plot. Given that the leaching behavior of atrazine was similar to that of simazine, the combined effect of low leaching potential and recharge rate in this area resulted in a very low atrazine load at $0.5 \mathrm{~m}$ depth (see Fig. 4b). As a result, a comparison of leaching (loss) estimates using EAF can be made across various contaminants as well as among states for a given chemical, as long as historical records of each pesticide application remain available as spatial data products.

\subsection{Known issues related to the index EAF}

The US federal leaching assessment tools such as SCI-GROW of US EPA and statistical regression models of USGS, except for WIN-PST of USDA that provided risk rating classes, predicted concentrations of pesticide residues in groundwater. This indicates that these tools are developed based on actual groundwater quality data, so perform best in specific areas where they are evaluated and validated (e.g., sandy, permeable soils for SCI-GROW and agricultural land for regressionbased models). In contrast, the index EAF estimated the mass fraction at a specific soil depth (in the root zone) using a physically based screening approach (i.e., simple advective flow and fate processes). It is applied to all mapped soils that contain the physical parameters required in the model, but its output cannot be directly compared with groundwater monitoring data assessed for each site. This is because not only do the observation wells range in depth from $0 \mathrm{~m}$ to $1168 \mathrm{~m}$ deep across the US mainland (Bell and Williamson, 2006), but also there are many factors (i.e., biogeochemical and hydrogeologic processes) affecting groundwater quality in space and time. Note also that there is a difference in units of measurement between these two sets of data (i.e., the predicted mass us observed concentration). Due to these reasons, we observed a very weak correlation between the two data sets for all chemicals examined (data not shown).

As spatial resolution of input data was also found to affect modeling results in watershed hydrology and water quality, we compared the difference in contaminant leaching between STASTGO2 and SSURGO (Fig. 7). The leaching potential of simazine for Mariposa County (in California) is illustrated in Fig. 7a (for STATSGO2) and b (for SSURGO), whereas that of Custer County (in Nebraska) is shown in Fig. 7b (for STATSGO2) and d (for SSURGO). As described in Fig. 3, a color index indicates the risk related to leaching of the target pollutant at a soil depth of $0.5 \mathrm{~m}$. From Fig. $7 \mathrm{a}-\mathrm{d}$, there was a clear difference in simazine leaching between STATSGO2 and SSURGO for both Mariposa and Custer Counties. Specifically, the observed difference between STATSGO2 and SSURGO appeared to be more significant in Mariposa County (i.e., high recharge areas) than in Custer County (i.e., low recharge 
(a)

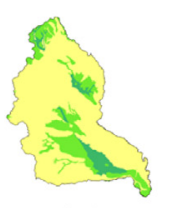

Oct.

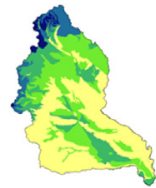

Apr.

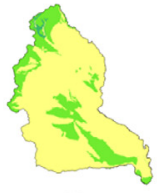

Nov

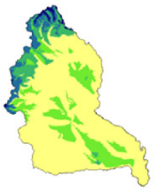

May

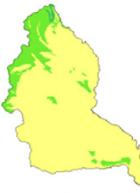

Dec.

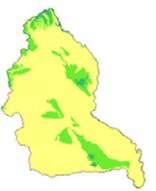

Jun.

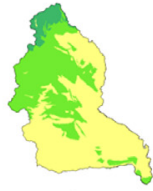

Jan.

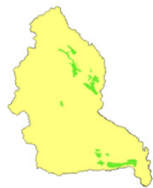

Jul.

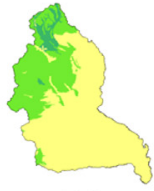

Feb.

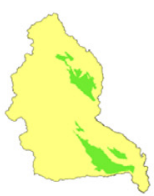

Aug.

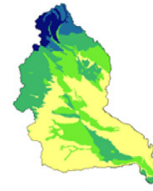

Mar.

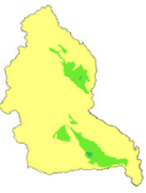

Sep. (m/day)

$0.000000-0.000452$

$0.000453-0.001501$

$0.001502-0.004158$

$0.004159-0.007902$

$0.007903-0.015692$

(b)

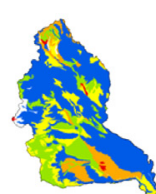

Oct.

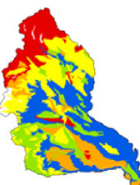

Apr.

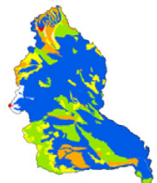

Nov

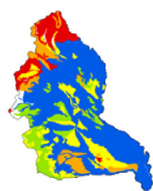

May

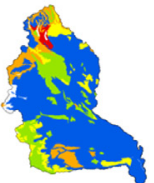

Dec.

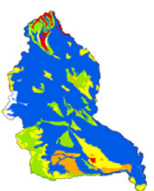

Jun.

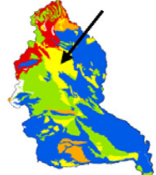

Jan.

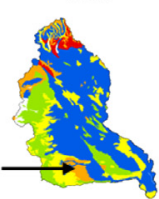

Jul.

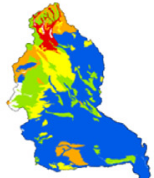

Feb.

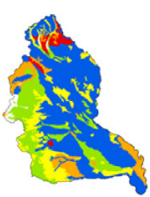

Aug.

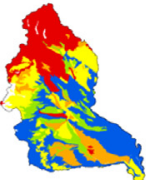

Mar.

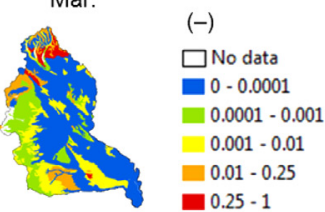

Sep.

Fig. 5 - (a) Monthly recharge rates for the Yakima River Basin Aquifer System for water year 2001 (see Table 1 and Fig. 1b) and (b) the corresponding variations in simazine leaching. In (b), color index indicates a leaching fraction of a chemical at $0.5 \mathrm{~m}$ depth; blank (no data), 0-0.0001 (very low), 0.0001-0.001 (low), 0.001-0.01 (medium), 0.01-0.25 (high), and 0.25-1 (very high). (For interpretation of the references to color in this figure legend, the reader is referred to the web version of this article.)

(a)

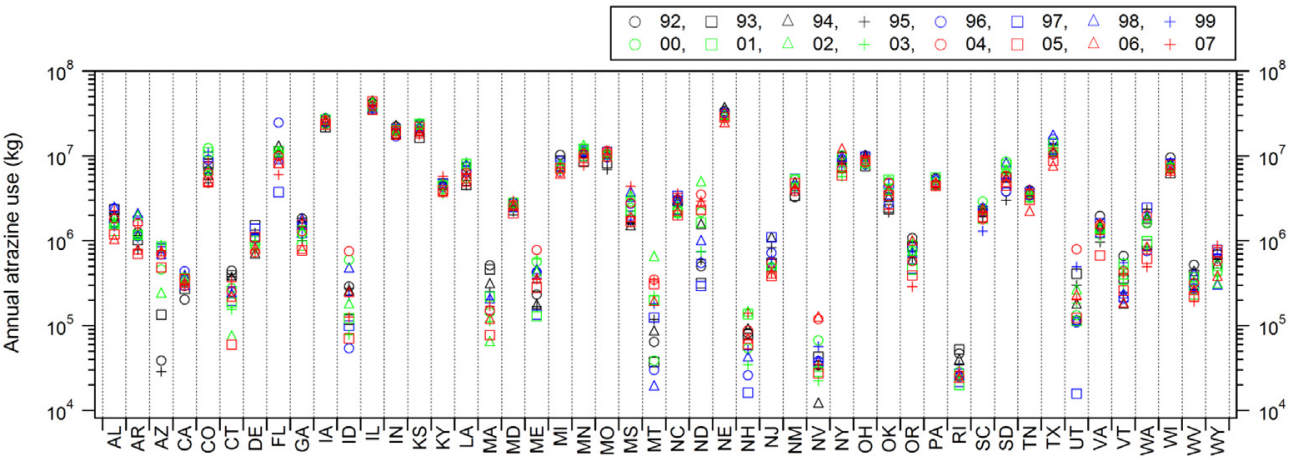

(b)

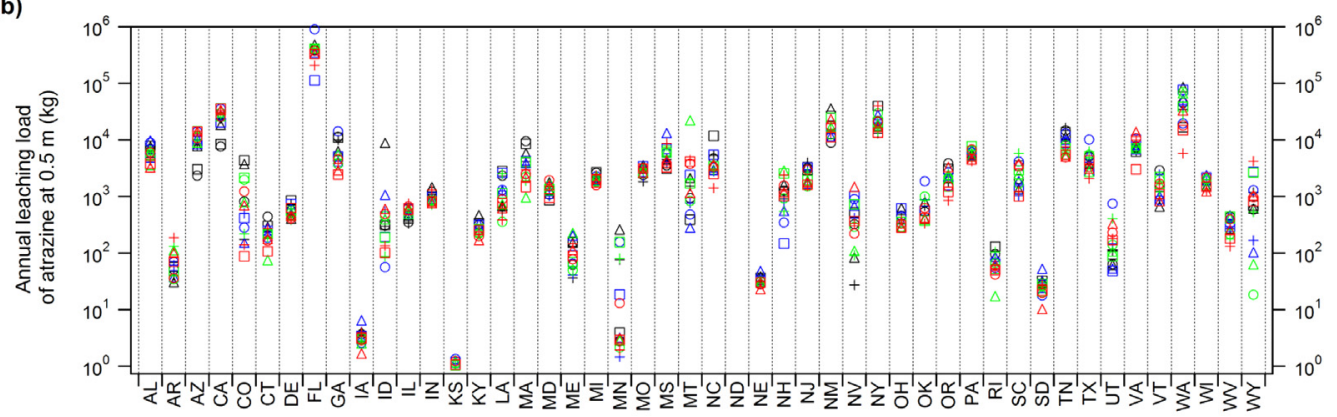

48 states in the United States

Fig. 6 - (a) Historical use of atrazine (kg) aggregated to the 48 individual states from 1992 to 2007 (see Table 1) and (b) the corresponding variations in the mass loads of atrazine $(\mathrm{kg})$ at $0.5 \mathrm{~m}$ depth. 


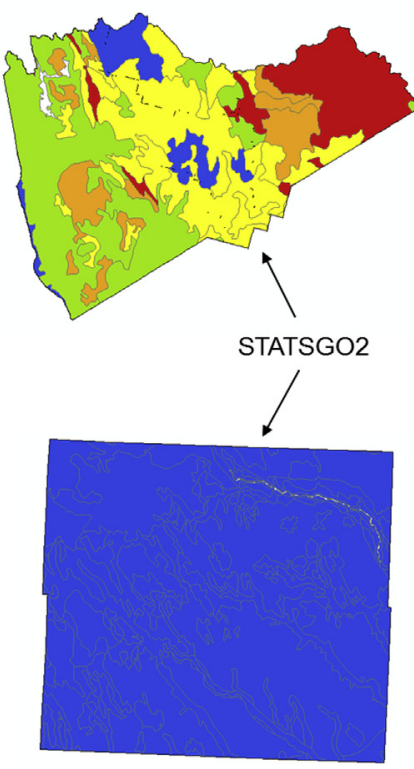

(b)

(d)

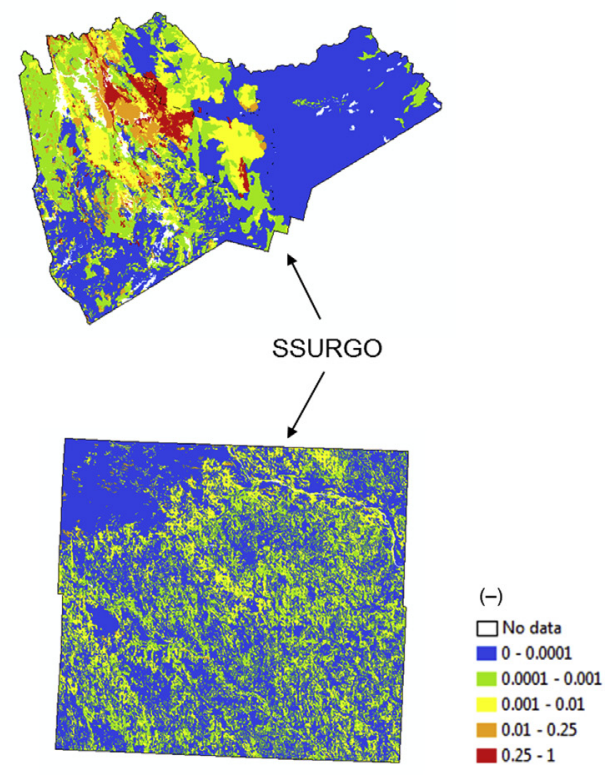

Fig. 7 - Difference in simazine leaching at $0.5 \mathrm{~m}$ depth between STATSGO2 and SSURGO for two example counties in the United States mainland; Mariposa County (in California) using (a) STATSGO2 and (b) SSURGO and Custer County (in Nebraska) using (c) STATSGO2 and (d) SSURGO (see Fig. 1b).

areas). In fact, this is mainly attributed to the difference of mapped soil properties between STATSGO2 and SSURGO (see Fig. A.2). The east side of Mariposa County that showed low risk using SSURGO was changed to high-risk leaching areas using STATSGO2, which exactly coincided with soils with high organic carbon content levels in SSURGO, and vice versa in STATSGO2. In addition, a minor difference in recharge rates was observed between two maps at different resolutions, which also affected the leaching potential of simazine, to a lesser extent. There will be some difference in output recharge maps when a set of grid points in a raster data set is averaged based on different numbers of soil polygons (i.e., low in STATSGO2 us high in SSURGO). In Mariposa County, the difference in recharge rates was more significant in soils with high organic carbon content levels than remaining areas (see Fig. A.2). The remaining soil properties such as $\rho_{b}$ and $\theta_{F C}$ appeared to play a minor role in the leaching assessment, as discussed in Section 3.1.1. From these results, a trade-off appears to be needed for quality of spatial input data to ensure effective use of EAF in leaching assessment at various spatial scales, from county- to national-levels.

Other disadvantages of the index EAF include limitations in its use within the depth of active root zone layer (up to $1 \mathrm{~m}$ ) and at high Peclect number (i.e., advection-dominated flow regime) (Hantush et al., 2002). In addition to this, there are also some restrictions on the soil profiles (which may not reach to $1 \mathrm{~m}$ depth) available in the national soil database (e.g., STATSGO or SSURGO) depending on geographic location. Below the root zone, the index EAF, however, can be still extended to include the intermediate vadose zone using the proposed approach in Hantush et al. (2002), as long as soil profiles within the depth of interest are available. In this case, the mass leaving the root zone $\left(M_{r}\right)$ becomes $M_{0 \_i}$ for the intermediate vadose zone. The product of attenuation factors in these two zones is then the mass fraction introduced to the water table. If the recharge rate is low, the dispersive-advective formula (Hantush et al., 2000, 2002) should be also employed in the index EAF. Nonetheless, we simply use the index EAF to examine the practical aspects of the screening tool utilizing various geospatial layers (published recently from the US federal agencies) for the national-scale soil vulnerability assessment.

\section{Conclusions}

In this study, we introduced a methodology to rapidly describe the leaching risk of agricultural chemicals at the national scale using a simple benchmark indicator EAF. New databases that included a list of parameters in EAF were compiled in a geographic information system with Visual Basic code, which allowed us to develop the national soil vulnerability maps for individual contaminants. Combining additional databases with each vulnerability map enabled a better understanding of the use and limitations of EAF in the context of leaching assessment on different scales. The major findings of this study are as follows.

- When four example chemicals were examined using EAF, picloram showed the highest leaching potential across the contiguous United States due to low $K_{o c}$ and long $T_{1 / 2}$ values, followed by simazine, 2,4-D, and glyphosate. The EAF predicted higher leaching load of picloram than simazine, 2,4-D, and glyphosate when combined with the aggregate amount of pesticides applied in 1997. In this regard, EAF can be used widely in pollutant leaching assessment because the standard DRASTIC method that assesses groundwater vulnerability to general 
contaminants (e.g., nitrate and phosphate) and pesticides does not elucidate the change in contaminant loads and the differentiation among contaminants unless modified for specific applications.

- Pollutant leaching assessed by EAF varied across (monthly) groundwater recharge rates as well as among temporal pesticide usage patterns (from 1992 to 2007). The contaminant leaching was high with increasing both recharge rates and pesticide use intensity. However, there were also many soils that showed excellent and poor capabilities for pollutant attenuation intrinsically. In this way, areas most vulnerable to various soil and groundwater contaminants can be easily identified. Specifically, EAF can be universally applied to most areas of the US mainland in which soil data are available, as compared with SCI-GROW in US EPA and other regression models in USGS that are developed in shallow groundwater or agricultural areas. Note that a direct comparison of pesticide contamination is not made between EAF and actual (monitored) groundwater quality data at this moment due to the difference in compliance depths and various environmental factors, in addition to units of measurement. There are some limitations on screening ability of the current index EAF which performs best in shallow soils under high recharge conditions. We propose two follow-up methods that can extend EAF beyond the root zone as well as in low recharge rate.

- Like many issues that arise in water quality modeling, SSURGO provided a more detailed explanation of contaminant leaching from EAF than STATSGO2. The difference in chemical leaching between SSURGO and STATSGO2 was larger in high recharge areas than low recharge areas. However, this is due largely to structural differences between two soil maps that provide soil physical properties in general and in detail. To some degree, the difference in output recharge maps captured by different numbers of soil polygons was also found to affect the leaching potential. As different types of data will be available from many local studies, we therefore recommend to maintain the proper balance between soil and recharge maps in terms of spatial resolution when applying EAF at different scales. Prediction accuracy may vary considerably across different models (e.g., higher tier leaching models) and contaminants as well as among environmental conditions (or locations). Therefore, further research is warranted to address more in-depth benefits and drawbacks of EAF us other models based on data availability.

\section{Acknowledgments}

This research was supported by two projects under the Safe Drinking Water Branch in the Hawaii State Department of Health: "Modeling to support monitoring waiver for selected wells in Hawaii (project number 4500114; grant number ASO LOG 14-106)" and "Development of an enhanced groundwater vulnerability tool in Hawaii for pharmaceuticals (project number 6102315; grant number ASO LOG 14-164)". The authors gratefully acknowledge the support of geospatial data provided by the United States (US) federal agencies, the US Department of Agriculture and US Geological Survey. The research has not been subject to the US Environmental Protection Agency review. Therefore, it does not necessarily reflect the views of the agency and no official endorsement should be inferred.

\section{Nomenclature}

AF an indicator of soil attenuation capacity only for non-volatile chemicals

ArcGIS a software for management, analysis and visualization of geographic data

DPM a water-budget model for deep drainage (i.e., groundwater recharge)

DRASTIC a method for providing a general overview of groundwater vulnerability to environmental pollutants

EAF an indicator of soil attenuation capacity for volatile and non-volatile chemicals

ERF an indicator of soil retardation capacity for volatile and non-volatile chemicals

HRUs homogeneous spatial units discretized (or subdivided) from each sub-basin

HYDRUS a numerical model in one-, two-, and threedimensional variably saturated media

MACRO a one-dimensional, preferential flow model in macroporous soil

MUKEY an identifier of having a numerical key for the map unit (i.e., soil polygon)

MUSYM an identifier of labeling each soil series for the map unit (i.e., soil polygon)

PRMS a distributed-parameter modeling system for watershed hydrology

PRZM3 a one-dimensional model in the crop root zone $\mathrm{RF}$ an indicator of soil retardation capacity only for nonvolatile chemicals

SCI-GROW a screening model in shallow groundwater

SSURGO a digital soil map at high spatial resolution (at $1: 12,000$ or $1: 24,000$ scale)

STATSGO(2) a digital soil map at medium spatial resolution (at 1:250,000 scale)

VB a high-level programming language evolved from a BASIC program

WIN-PST a pesticide environmental risk screening tool

\section{Appendix A. Supplementary data}

Supplementary data related to this article can be found at http://dx.doi.org/10.1016/j.watres.2015.03.009.

\section{R E F E R E N C E S}

Bell, R.W., Williamson, A.K., 2006. Data Delivery and Mapping over the Web-National Water-Quality Assessment Data Warehouse. U.S. Geological Survey (USGS) Fact Sheet 2006- 
3101, 6 p. USGS, Reston, Virginia, USA. Available online at: http://pubs.usgs.gov/fs/2006/3101/pdf/fs06-3101_508.pdf.

Beulke, S., Renaud, F., Brown, C.D., 2002. Development of Guidance on Parameter Estimation for the Preferential Flow Model MACRO 4.2. DEFRA Project PL0538, 68 p. Cranfield Centre for EcoChemistry, Cranfield University, Silsoe, Central Bedfordshire, UK. Available online at: http://www.pesticides. gov.uk/Resources/CRD/Migrated-Resources/Documents/R/ Research_PL0538-MACROparameterisation.pdf.

Brown, J., Bach, L., Aldous, A., Wyers, A., DeGagne, J., 2011. Groundwater-dependent ecosystems in Oregon: an assessment of their distribution and associated threats. Front. Ecol. Environ. 9 (2), 97-102.

Dusek, J., Dohnal, M., Vogel, T., Ray, C., 2011. Field leaching of pesticides at five test sites in Hawaii: modeling flow and transport. Pest Manag. Sci. 67 (12), 1571-1582.

Gassman, P.W., Reyes, M.R., Green, C.H., Arnold, J.G., 2007. The soil and water assessment tool: historical development, applications, and future research directions. Trans. ASABE 50 (4), 1211-1250.

Gilliom, R.J., Barbash, J.E., Crawford, C.G., Hamilton, P.A., Martin, J.D., Nakagaki, N., Nowell, L.H., Scott, J.C., Stackelberg, P.E., Thelin, G.P., Wolock, D.M., 2006. The Quality of Our Nation's Waters-Pesticides in the Nation's Streams and Ground Water, 1992-2001. U.S. Geological Survey (USGS) Circular 1291, 172 p. USGS, Reston, Virginia, USA. Available online at: http://pubs.usgs.gov/circ/2005/1291/pdf/circ1291.pdf.

Hantush, M.M., Govindaraju, R.S., Marino, M.A., Zhang, Z.L., 2002. Screening model for volatile pollutants in dual porosity soils. J. Hydrol. 260 (1-4), 58-74.

Hantush, M.M., Mariño, M.A., Islam, M.R., 2000. Models for leaching of pesticides in soils and groundwater. J. Hydrol. 227 (1-4), 66-83.

Herner, A.E., Acock, B., 2003. USDA-ARS Pesticide Properties Database. Encyclopedia of Agrochemicals. John Wiley \& Sons, Inc., Hoboken, New Jersey, USA http://dx.doi.org/10.1002/ 047126363X.agr237. Available online at: http://www.ars.usda. gov/Main/docs.htm?docid=14199.

Holman, I.P., Dubus, I.G., Hollis, J.M., Brown, C.D., 2004. Using a linked soil model emulator and unsaturated zone leaching model to account for preferential flow when assessing the spatially distributed risk of pesticide leaching to groundwater in England and Wales. Sci. Total Environ. 318 (1-3), 73-88.

Ki, S.J., Ray, C., 2015. A GIS-assisted regional screening tool to evaluate the leaching potential of volatile and non-volatile pesticides. J. Hydrol. 522, 163-173.

Lawrence, S.J., 2006. Description, Properties, and Degradation of Selected Volatile Organic Compounds Detected in Ground Water-A Review of Selected Literature. U.S. Geological Survey (USGS) Open-File Report 2006-1338, 62 p. USGS, Atlanta, Georgia, USA. Available online at: http://pubs.usgs.gov/of/ 2006/1338/pdf/ofr2006-1338.pdf.

Mackay, D., Shiu, W.Y., Ma, K.C., Lee, S.C., 2006 Handbook of Physical-chemical Properties and Environmental Fate for Organic Chemicals, second ed., vol. I-IV. CRC Press, Boca Raton, Florida, USA.

Nolan, B.T., Hitt, K.J., 2006. Vulnerability of shallow groundwater and drinking-water wells to nitrate in the United States. Environ. Sci. Technol. 40 (24), 7834-7840.

Pereira, A.S., Cerejeira, M.J., Daam, M.A., 2014. Comparing ecotoxicological standards of plant protection products potentially toxic to groundwater life with their measured and modelled concentrations. Ecotoxicol. Environ. Saf. 102, 152-159.

Risser, D.W., Gburek, W.J., Folmar, G.J., 2005. Comparison of Methods for Estimating Ground-water Recharge and Base Flow at a Small Watershed Underlain by Fractured Bedrock in the Eastern United States. U.S. Geological Survey Scientific Investigations Report 2005-5038, 31 p. USGS, Reston, Virginia,
USA. Available online at: http://pubs.usgs.gov/sir/2005/5038/ pdf/sir2005-5038.pdf.

Šimůnek, J., van Genuchten, M.T., 2008. Modeling nonequilibrium flow and transport processes using HYDRUS. Vadose Zone J. 7 (2), 782-797.

Šimůnek, J., 2005. Models of water flow and solute transport in the unsaturated zone. In: Anderson, M.G., McDonnell, J.J. (Eds.), Encyclopedia of Hydrological Sciences. John Wiley \& Sons, Ltd., Chichester, West Sussex, UK, pp. 1171-1180. Available online at: http://www.pc-progress.com/Documents/ Jirka/Encyclopedia-Simunek_1171-1180.pdf.

Šimůnek, J., van Genuchten, M.T., Sejna, M., 2008. Development and applications of the HYDRUS and STANMOD software packages and related codes. Vadose Zone J. 7 (2), 587-600.

Soil Survey Staff, 2013a. Natural Resources Conservation Service, United States Department of Agriculture. Soil Survey Geographic (SSURGO) Database. Available online at: http:// sdmdataaccess.nrcs.usda.gov/.

Soil Survey Staff, 2013b. Natural Resources Conservation Service, United States Department of Agriculture. U.S. General Soil Map (STATSGO2). Available online at: http://sdmdataaccess. nrcs.usda.gov/.

Squillace, P.J., Scott, J.C., Moran, M.J., Nolan, B.T., Kolpin, D.W., 2002. VOCs, pesticides, nitrate, and their mixtures in groundwater used for drinking water in the United States. Environ. Sci. Technol. 36 (9), 1923-1930.

Stackelberg, P.E., Barbash, J.E., Gilliom, R.J., Stone, W.W., Wolock, D.M., 2012. Regression models for estimating concentrations of atrazine plus deethylatrazine in shallow groundwater in agricultural areas of the United States. J. Environ. Qual. 41 (2), 479-494.

Stenemo, F., Ray, C., Yost, R., Matsuda, S., 2007. A screening tool for vulnerability assessment of pesticide leaching to groundwater for the islands of Hawaii, USA. Pest Manag. Sci. 63 (4), 404-411.

U.S. Environmental Protection Agency (US EPA), 1997. State Source Water Assessment and Protection Programs Guidance. Final Guidance. Report number 816-R-97-009. Office of Water, Washington, DC, USA. Available online at: http://www.epa. gov/safewater/sourcewater/pubs/swpguidance.pdf.

University of Hertfordshire (UH), 2013. The Pesticide Properties DataBase (PPDB) Developed by the Agriculture \& Environment Research Unit (AERU). UH, 2006-2013, Hatfield, Hertfordshire, UK. Available online at: http://sitem.herts.ac.uk/aeru/ppdb/en/.

Vaccaro, J.J., Olsen, T.D., 2007. Estimates of Ground-water Recharge to the Yakima River Basin Aquifer System, Washington, for Predevelopment and Current Land-use and Land-cover Conditions. U.S. Geological Survey Scientific Investigations Report 2007-5007, 30 p. USGS, Reston, Virginia, USA. Available online at: http://pubs.usgs.gov/sir/2007/5007/ pdf/sir20075007.pdf.

Vanclooster, M., Boesten, J.J.T.I., Trevisan, M., Brown, C.D., Capri, E., Eklo, O.M., Gottesbüren, B., Gouy, V., van der Linden, A.M.A., 2000. A European test of pesticide-leaching models: methodology and major recommendations. Agric. Water Manag. 44 (1-3), 1-19.

Wolock, D.M., 2003. Estimated Mean Annual Natural Groundwater Recharge in the Conterminous United States. U.S. Geological Survey Open-File Report 03-311, digital data set. USGS, Reston, Virginia, USA. Available online at: http://water. usgs.gov/lookup/getspatial?rech48grd.

Zogorski, J.S., Carter, J.M., Ivahnenko, Tamara, Lapham, W.W., Moran, M.J., Rowe, B.L., Squillace, P.J., Toccalino, P.L., 2006. The Quality of Our Nation's Waters-Volatile Organic Compounds in the Nation's Ground Water and DrinkingWater Supply Wells. U.S. Geological Survey (USGS) Circular 1292, 101 p. USGS, Reston, Virginia, USA. Available online at: http://pubs.usgs.gov/circ/circ1292/pdf/circular1292.pdf. 